Jpn. J. Genet. (1981) 56, pp. 397-407

\title{
Genetic control of alcohol dehydrogenase in the Japanese species of Trillium
}

\author{
By Masaaki IHARA ${ }^{1)}$ and Toru Endo \\ Department of Botany, University of Tokyo, \\ Tokyo 113 \\ and \\ Department of Biochemistry, National Institute of Genetics, \\ Mishima 411
}

(Received August 4, 1980)

\begin{abstract}
Endosperm alcohol dehydrogenase (ADH) was investigated electrophoretically in T. kamtschaticum Pall. $\left(2 \mathrm{n}=10 ; \mathrm{K}_{1} \mathrm{~K}_{1}\right)$, T. tschonoskii Maxim. $(2 \mathrm{n}=20$; $\left.\mathrm{K}_{2} \mathrm{~K}_{2} \mathrm{TT}\right)$, T. smallii Maxim. $\left(2 \mathrm{n}=20\right.$; SSUU) and their $\mathrm{F}_{1}$ hybrids. Main electrophoretic phenotypes so far detected are composed of fast, slow and intermediately moving bands. We denote them for convenience as F, S and $\mathrm{H}$ bands, respectively. T. kamtschaticum shows only $\mathrm{F}$ band; T. tschonoskii has two visible and one concealed $S$ bands, viz., the main slowest band $\left(S_{1}\right)$, a hybrid band $\left(\mathrm{S}_{2}\right)$ and slightly faster but concealed band $\left(\mathrm{S}_{8}\right) ; T$. smallii reveals all three main bands or FS pattern. All the $F_{1}$ progeny of interspecific crosses exhibit the FS pattern. We assign the following alleles for respective ADH isozymes of each entity: $A d h^{F(K)}$ in T. kamtschaticum, $A d h^{S_{1}(T)}$ and $A d h^{S_{2}(T)}$ in T. tschonoskii and $A d h^{F(S)}$ and $A d h^{S(S)}$ in T. smallii. In vitro dissociation-recombination experiment demonstrates that these isozymes are dimers. These isozymes exhibit substrate specificity for alcohols with $-\mathrm{CH}_{2} \mathrm{OH}$ radical remarkably, viz., the highest activity for ethanol and n-propyl alcohol but inert for isopropyl alcohol and so forth.
\end{abstract}

\section{INTRODUCTION}

Although extensive works have been done for cytogenetical and population studies of the Japanese species of Trillium (Haga 1934, 1937, 1951, 1958, 1969; Haga and Kurabayashi 1952; Haga et al. 1974; Kurabayashi 1952; Kurabayashi and Saho 1957; Narise 1956; Hiraizumi 1956; Fukuda 1967; Kayano and Watanabe 1970 and others), none of electrophoretic studies have been employed for the investigation of the species. Information of genetic control of direct products of genes is promissing for a better understanding of genetic structure of populations; to this end it has been tried to establish genetics of various electromorphs in Trillium.

This paper describes genetic control of the electromorphs of alcohol dehydrogenase (E.C. 1.1.1.1, ADH) of seeds. A preliminary report of the present observation has been presented elsewhere (Thara and Endo 1978).

1) Present address: 332-1, Naka, Mishima, 411 


\section{MATERIALS AND METHODS}

Materials: Trilliums used in the study were collected from localities listed on Table 1 and transplanted to the Botanical Gardens, Koishikawa, University of Tokyo and to the Nikko Botanical Garden, University of Tokyo, where crossing experiments were made.

Electrophoresis: The seeds were either used immediately or after storage at $4-8^{\circ} \mathrm{C}$ for periods of up to one (rarely two) years. The extraction of the enzyme was made by grinding one seed in a mortar and pestle with a small amount of qualtz sand and ca. $0.1 \mathrm{ml}$ of $1 \% 2$-mercaptoethanol in $50 \mathrm{mM}$ Tris$\mathrm{HCl}$ buffer ( $\mathrm{pH} \mathrm{7.0)}$ at room temperature. We have employed the above procedure also at $4^{\circ} \mathrm{C}$ by the aid of Kubota Hematocrit model KH-120 centrifuge at various speeds and times, but no appreciable improvement was obtained for the ADH bandmorphs. The crude extract was absorbed onto a $5 \times 9 \mathrm{~mm}$ or $5 \times 18 \mathrm{~mm}$ wick of Toyo \#50 (0.27 mm thick) filter paper and the wicks were inserted into a $10 \%$ starch gel mediated with borate- $\mathrm{NaOH}$ buffer ( $\mathrm{pH} 8.5)$. The samples were run at either $150 \mathrm{~V}$ for $2.5 \mathrm{~h}$ or $250 \mathrm{~V}$ for $3.0 \mathrm{~h}$ with use of a Toyo electrophoretic apparatus in a refrigerator $\left(8^{\circ} \mathrm{C}\right)$. The gels subjected to electrophoresis were sliced horizontally and stained over night at room temperature in the staining mixture described by Schwartz and Endo (1966) with a minor modification. The assay was repeated twice without substrate for the confirmation of the specificity of the enzyme. Various forms of alcohol were tested for their applicability to the substrate (cf. Table 4).

Dissociation-recombination test: Enzyme extracts were made from $100 \mathrm{mg}$ of seeds in each sample, ground separately in a mortar and pestle with $0.4 \mathrm{ml}$ of $0.1 \mathrm{M}$ phosphate buffer ( $\mathrm{pH} 6.8$ ) containing $0.1 \mathrm{M} 2$-mercaptoethanol, $1 \mathrm{M} \mathrm{NaCl}$ and $0.4 \mathrm{M}$ sucrose; then the slurry was centrifuged at $12,000 \mathrm{rpm}$ for $60 \mathrm{~min}$ at $0^{\circ} \mathrm{C}$. The supernatant thus obtained was subjected to the following processes: equal amount of respective supernatants was mixed and kept at $-30^{\circ} \mathrm{C}$ for more than $12 \mathrm{~h}$, followed by a $2-4 \mathrm{~h}$ dialysis against the extracting solution

Table 1. Original localities of the materials employed in the study

\begin{tabular}{ll}
\hline Population name & \multicolumn{1}{c}{ Location } \\
\hline Hosoo & $\begin{array}{l}\text { ca. } 1 \mathrm{~km} \text { NW of Hosoo, Nikko, Tochigi-ken; about half way of S folk } \\
\text { of the Daiya River. } \\
\text { ca. } 4 \mathrm{~km} \text { E of Torisawa sta., Chuo line of JNR; ca. 0.5 km above junct. } \\
\text { of a stream on the N-facing slope to the foot-path toward Mt. Kura- } \\
\text { take, Yamanashi-ken. } \\
\text { ca. } 1 \mathrm{~km} \text { SE of Kuzakai sta., Miyako line of JNR; at the margin of } \\
\text { deciduous woods along stream. } \\
\text { Kuzakai }\end{array}$ \\
ca. $3 \mathrm{~km}$ NW of Nanae sta., Hakodate line of JNR; ca. 0.5 km N of \\
junct. of Hwy 5 to a local drive at Narukawa-cho, Hakodate.
\end{tabular}


except $\mathrm{NaCl}$ at $4^{\circ} \mathrm{C}$. The samples were run at $250 \mathrm{~V}$ for $4.0 \mathrm{~h}$, and the same enzyme assay was made for detecting hybridized enzymes.

Densitometry: Each assayed gel was scanned by a Toyo Densitorol DMU-2 densitometer at $624 \mathrm{~nm}$ and the absorption curves were drawn automatically.

\section{RESULTS}

Electrophoretic patterns of alcohol dehydrogenase

Three species examined show remarkable differences with respect to electrophoretic patterns of the enzyme (Table 2 and Fig. 1). All three patterns were observed anodally. The " $F$ pattern" refers to a fast migrating single band, observed in T. kamtschaticum (Figs. 1c, 1c'). The "S pattern" consists of slow moving band(s), observed in T. tschonoskii. By a 150V electrophoresis, only a single band is shown and the band is separable by a high voltage (more than $200 \mathrm{~V}$ ) into the main band $\left(\mathrm{S}_{1}\right)$ and a slightly faster and faintly stained band $\left(\mathbf{S}_{2}\right)$. In the previous report (Ihara and Endo 1978), the $S_{2}$ band was regarded as a ghost band but it recovers in the bandmorphs of the $F_{1}$ progeny (Figs. 1b, 1b') The "FS pattern", in which a fast, a slow and an intermediately migrating bands are seen, occurs in T. smallii. The fast moving band stains about 1/10 as intensely as the slow band (Figs. 1a, 1a').

Electromorphs in the $F_{1}$ progeny

All possible crosses were made and respective progenies were examined electrophoretically (Table 3). The result is clear: Only the FS pattern appeared in every cross (Fig. 2). A new band which occurs in the $F_{1}$ bandmorphs of the kamtschaticum $\times$ tschonoskii and tschonoskii $\times$ kamtschaticum crosses is a hybrid one or $\mathrm{H}$ bandmorph, showing an intermediate mobility between the fast and the main slow bands specific to progenitors. Since the hybrid band overlaps the middle band of $T$. smallii, the main slow and fast moving isozymes,

Table 2. Frequencies of electrophoretic patterns observed in self-pollinated $F_{1}$ progenies of three species

\begin{tabular}{|c|c|c|c|c|c|}
\hline \multirow{2}{*}{$\begin{array}{c}\text { Species } \\
\text { (genomic form) }\end{array}$} & \multirow{2}{*}{$\begin{array}{l}\text { Population } \\
\text { name }\end{array}$} & \multirow{2}{*}{$\begin{array}{l}\text { No. of seeds } \\
\text { examined }\end{array}$} & \multicolumn{3}{|c|}{ Electrophoretic patterns (\%) } \\
\hline & & & $\mathbf{F}$ & FS & $\mathbf{S}$ \\
\hline T. kamtschaticum & Nanae & 109 & 100 & $\mathbf{0}$ & 0 \\
\hline$\left(\mathrm{K}_{1} \mathrm{~K}_{1}\right)$ & Kuzakai & 184 & 100 & $\mathbf{0}$ & 0 \\
\hline T. tschonoskii & Hosoo & 59 & 0 & 0 & 100 \\
\hline$\left(\mathrm{K}_{2} \mathrm{~K}_{\mathbf{2}} \mathrm{TT}\right)$ & Kuratake & 119 & $\mathbf{0}$ & 0 & 100 \\
\hline T. smallii & Hosoo & 109 & 0 & 100 & 0 \\
\hline (SSUU) & Kuratake & 91 & $\mathbf{0}$ & 100 & 0 \\
\hline
\end{tabular}




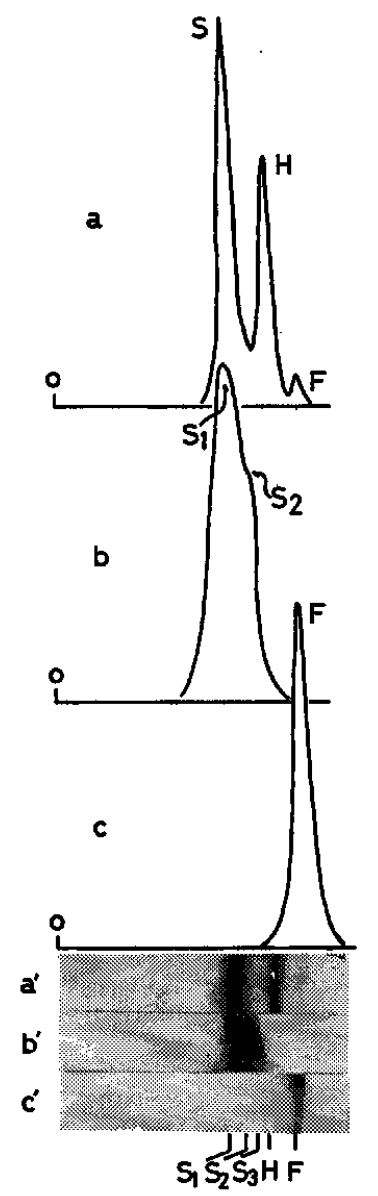

Fig. 1. Electrophoretic patterns shown by zymograms $\left(\mathrm{a}^{\prime}-\mathrm{c}^{\prime}\right)$ and $624 \mathrm{~nm}$ absorption spectra (a-c) of the endosperm ADH in the Japanese species of Trillium. FS pattern in T. smallii $\left(\mathrm{a}, \mathrm{a}^{\prime}\right)$, S pattern in T. tschonoskii $\left(\mathrm{b}, \mathrm{b}^{\prime}\right)$ and $\mathrm{F}$ pattern in T. kamtschaticum (c, $\left.\mathrm{c}^{\prime}\right)$. Abbreviation: o, original spot. $\mathrm{S}$, slow migrating band. $\mathrm{H}$, hybrid band. F, fast moving band. Note the enzyme activity of $\mathrm{S}$ band to be approximately 0.1 -fold intensity of $\mathrm{F}$ band in $T$. smallii. The zymograms were obtained by electrophoresis at $250 \mathrm{~V}$ for $3.5 \mathrm{~h}$.

each showing the same mobility in species tested, may be specified by respective common alleles.

In vitro dissociation-recombination of the enzyme

As shown in the previous section, a hybrid bandmorph was detected on the zymograms of the $\mathrm{F}_{1}$ progenies recovered from the kamtschaticum $\times$ tschonoskii and tschonoskii $\times$ kamtschaticum crosses. This suggests that the functional enzyme is dimeric, consisting of two polypeptide subunits as known in the 
Table 3. Frequencies of electrophoretic phenotypes observed in the $\boldsymbol{F}_{1}$ progenies of interspecific crosses

\begin{tabular}{|c|c|c|c|c|c|c|}
\hline \multirow{2}{*}{ Female parents } & \multirow{2}{*}{ Male parents } & \multirow{2}{*}{ Cross type* } & \multirow{2}{*}{$\begin{array}{l}\text { No. of } \\
\text { progeny } \\
\text { examined }\end{array}$} & \multicolumn{3}{|c|}{ Phenotypes detected (\%) } \\
\hline & & & & $\mathbf{F}$ & FS & $\mathbf{S}$ \\
\hline kamtschaticum & tschonoskii & $\mathrm{Nn} \times \mathrm{Hs}$ & 6 & 0 & 100 & 0 \\
\hline tschonoskii & kamtschaticum & $\mathrm{Hs} \times \mathrm{Nn}$ & 98 & 0 & 100 & 0 \\
\hline kamtschaticum & smaillii & $\mathrm{Nn} \times \mathbf{K r}$ & 18 & $\mathbf{0}$ & 100 & 0 \\
\hline smallii & kamtschaticum & $\mathrm{Hs} \times \mathrm{Nn}$ & 24 & $\mathbf{0}$ & 100 & 0 \\
\hline tschonoskii & smallii & $\mathrm{Hs} \times \mathrm{Hs}$ & 43 & 0 & 100 & 0 \\
\hline smallii & tschonoskii & $\mathrm{Hs} \times \mathrm{Hs}$ & 43 & $\mathbf{0}$ & 100 & $\mathbf{0}$ \\
\hline
\end{tabular}

* Sources of materials are indicated (cf. Table 1 for abbreviation).

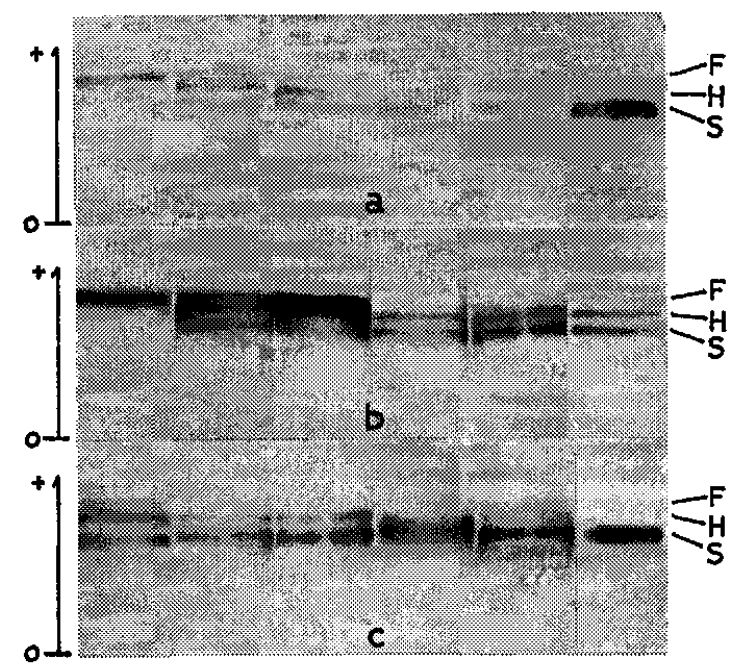

Fig. 2. Zymograms showing bandmorphs of parental species and their $F_{1}$ progenies. From left to right, (a) T. kamtschaticum (K), $\mathrm{K} \times \mathrm{T}, \mathrm{K} \times \mathrm{T}, \mathrm{T} \times \mathrm{K}, \mathrm{T} \times \mathrm{K}, T$. tschonoskii (T); (b) $\mathrm{K}, \mathrm{K} \times \mathrm{S}, \mathrm{K} \times \mathrm{S}, \mathrm{S} \times \mathrm{K}, \mathrm{S} \times \mathrm{K}, T$, smallii (S); (c) $\mathrm{S}, \mathrm{S} \times \mathrm{T}, \mathrm{S} \times \mathrm{T}, \mathrm{T} \times \mathrm{S}$, $\mathrm{T} \times \mathrm{S}, \mathrm{T}$.

ADH isozymes of the other plant species, e.g., wheat (Hart 1971), maize (Fischer and Schwartz 1973) and sunflower (Torres 1976).

Demonstration of the dimer hypothesis was carried out by in vitro hybridization of different ADH polypeptide subunits occurring in T. kamtschaticum and $T$. tschonoskii, followed by detecting its resultants on the zymograms (Fig. 3). Results indicate that the seed ADH isozymes are dimers. It is noteworthy that the $\mathrm{FS}_{2}$ heterodimer did not show appreciable intensities, suggesting either an inhibited dimerization of the dimer or any structural deficiency. 


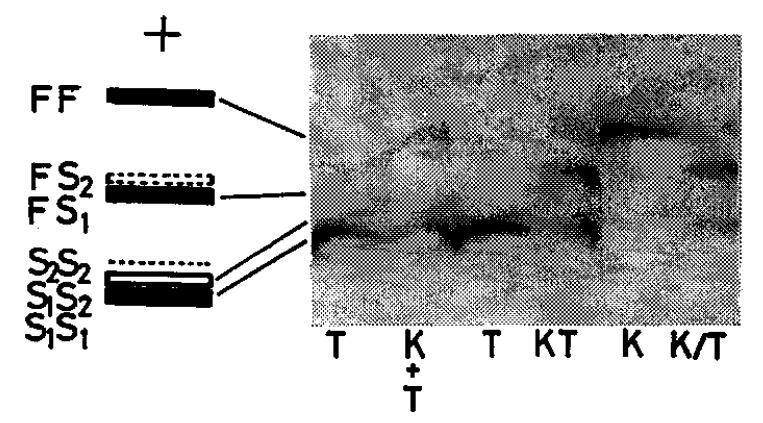

(a)

(b)

Fig. 3. Supposed (a) and actual (b) zymograms of in vitro hybridized dimers. (a) New dimers $\left(\mathrm{FS}_{1} \mathrm{FS}_{2}\right)$ are expected to occur from monomerized isozymes in $T$. kamtschaticum (FF) and $T$. tschonoskii $\left(\mathrm{S}_{1} \mathrm{~S}_{1}, \mathrm{~S}_{1} \mathrm{~S}_{2}, \mathbf{S}_{2} \mathrm{~S}_{2}\right)$. Thickness of lines represents approximate staining intensities expected. (b) Comparison among zymograms. From left to right, T, K+T, T, KT, $\mathrm{K}$ and $\mathrm{K} / \mathrm{T}$. Abbreviation: -, Anode; $\mathrm{K}$, enzyme of kamtschaticum; $\mathrm{T}$, enzyme of tschonoskii; $\mathrm{K}+\mathrm{T}$, two enzyme extracts mixed after dissociation-recombination had taken place; $K T$, enzyme of the $F_{1}$ progeny of the kamtschaticum $\times$ tschonoskii cross; $\mathrm{K} / \mathrm{T}$, a mixture of two enzymes subjected to the dissociation-recombination process.

Table 4. Substrate specificity of the endosperm ADH in Trillium

\begin{tabular}{|c|c|c|}
\hline Name & Fomula & Reactivity \\
\hline methyl alc. & $\mathrm{HCH}_{2} \mathrm{OH}$ & - \\
\hline ethyl alc. & $\mathrm{CH}_{3} \mathrm{CH}_{2} \mathrm{OH}$ & 姍 \\
\hline n-propyl alc. & $\mathrm{CH}_{8} \mathrm{CH}_{2} \mathrm{CH}_{2} \mathrm{OH}$ & \# \\
\hline iso-propyl alc. & $\left(\mathrm{CH}_{3}\right)_{2} \mathrm{CHOH}$ & - \\
\hline butyl alc. & $\mathrm{CH}_{8}\left(\mathrm{CH}_{2}\right)_{3} \mathrm{OH}$ & H \\
\hline iso-butyl alc. & $\left(\mathrm{CH}_{8}\right)_{2} \mathrm{CHCH}_{2} \mathrm{OH}$ & + \\
\hline sec. butyl alc. & $\mathrm{CH}_{3} \mathrm{CH}(\mathrm{OH}) \mathrm{CH}_{2} \mathrm{CH}_{3}$ & - \\
\hline tert. butyl alc. & $\left(\mathrm{CH}_{3}\right)_{3} \mathrm{COH}$ & - \\
\hline n-amyl alc. & $\mathrm{CH}_{3}\left(\mathrm{CH}_{2}\right)_{4} \mathrm{OH}$ & + \\
\hline n-hexyl ale. & $\mathrm{CH}_{8}\left(\mathrm{CH}_{2}\right)_{5} \mathrm{OH}$ & + \\
\hline n-octyl alc. & $\mathrm{CH}_{8}\left(\mathrm{CH}_{2}\right)_{6} \mathrm{OH}$ & + \\
\hline benzyl alc. & $\mathrm{C}_{6} \mathrm{H}_{5} \mathrm{CH}_{2} \mathrm{OH}$ & - \\
\hline DL- $\alpha$-phenyl ethyl alc. & $\mathrm{C}_{6} \mathrm{H}_{10} \mathrm{O}$ & - \\
\hline DL- $\beta$-phenyl ethyl alc. & $\mathrm{C}_{6} \mathrm{H}_{6}\left(\mathrm{CH}_{2}\right)_{2} \mathrm{OH}$ & - \\
\hline cinnamyl alc. & $\mathrm{C}_{9} \mathrm{H}_{10} \mathrm{O}$ & $\pm^{*}$ \\
\hline 2-mercaptoethanol & $\mathrm{HSCH}_{2} \mathrm{CH}_{2} \mathrm{OH}$ & - \\
\hline ethyleneglycol & $\mathrm{HOCH}_{2} \mathrm{CH}_{2} \mathrm{OH}$ & - \\
\hline ethyleneglycol-monoethylether & $\mathrm{C}_{2} \mathrm{H}_{5} \mathrm{OCH}_{2} \mathrm{CH}_{2} \mathrm{OH}$ & - \\
\hline
\end{tabular}

* Positive results were obtained twice in 6 trials. 


\section{Substrate specificity}

Various forms of alcohol were tested for their applicability to the substrate. As shown in Table 4, the seed ADH isozymes can utilize such alcohols as those with $-\mathrm{CH}_{2} \mathrm{OH}$ radical except methyl alcohol. Four aromatic alcohols were inert as the substrate, viz., benzyl alcohol, DL- $\alpha$ - and $\beta$-phenyl alcohol and cinnamyl alcohol. It was noted that staining intensities decreases as increase in molecular weight or $-\mathrm{CH}_{2}$ chain. These results are consistent with those in the potato ADH (cf. Davies et al. 1973).

\section{DISCUSSION}

\section{1) Allelic constitution}

Electrophoretic patterns of the ADH isozymes thus detected are governed at least 5 codominant alleles. They are designated as $A d h^{F(\pi)}, A d h^{s_{1}(T)}$, $A d h^{S_{2}(T)}, A d h^{F(S)}$ and $A d h^{S(S)}$, where $\mathrm{F}, \mathrm{S}_{1}$ and $\mathrm{S}_{2}$ represent fast and slow migrating isozymes and a variant of the slow one, respectively and letters in parenthesis refer to respective species bearing these alleles.

Assuming that the middle band of the FS pattern is a heterodimer derived from molecular hybridization between respective monomers of the fast and the slow moving isozymes, F, H and $\mathrm{S}$ bands would be a homo-, a hetero- and a homodimer of polypeptide subunits of the $\mathrm{ADH}$ isozymes, respectively. If the $S_{1}$ and $S_{2}$ bands of $T$. tschonoskii are a homodimer and a heterodimer, respectively, another homodimer would be visualized as a slightly faster moving bandmorph than the $S_{2}$. In fact, the supposed region on the zymograms is always blurred, suggesting the presence of an extremely less stained band. The concealed band is denoted as the $S_{s}$ band.

The lack of segregation of the FS pattern in all self-pollinated progeny of $T$. smallii suggests that the alleles specifying the pattern are homozygous at their respective loci, and it makes an equal allocation of allelic combination in each gamete. In the same manner, the seed $\mathrm{ADH}$ electromorphs of $T$. tschonoskii is explained as follows: The $S_{1}, S_{2}$ and $S_{8}$ bandmorphs are specified by the combination of two kinds of the Adh alleles, each of which locates on either $\mathrm{K}_{2}$ or $\mathrm{T}$ genomes which are transmitted into the same gamete.

\section{2) Gene dosage in the ADH activity}

If each allele locates on a particular genome, differences in the gene dosage result in the ADH activity, which is visualized as staining intensity of the bandmorphs. The relative staining intensity on the zymograms appear to be subjected to binomial expansion of the constituent polypeptide subunits of the isozyme (cf. Scandalios 1969).

Let $\alpha$ and $\beta$ be the number of the ADH alleles, each locating at $\mathrm{X}$ and $\mathrm{Y}$ 
genomes, respectively; let $1:(1+a) / 2$ a be the relative activity ratio of $\mathrm{F}^{\mathrm{x}} \mathrm{F}^{\mathrm{x}}$, $\mathrm{F}^{\mathrm{x}} \mathrm{S}^{\mathrm{y}}$ and $\mathrm{S}^{y} \mathrm{~S}^{y}$ dimers; let $1: \mathrm{m}$ be an yield of $\mathrm{F}^{\mathrm{x}}$ to $\mathrm{S}^{\mathrm{y}}$ monomer. We obtain kinds of dimers and their relative activities on the zymograms as follows.

$$
\left(\alpha \mathrm{F}^{\mathrm{x}}+\mathrm{m} \beta \mathrm{S}^{\mathrm{y}}\right)^{2} \longrightarrow \alpha^{2} \mathrm{~F}^{\mathrm{x}} \mathrm{F}^{\mathrm{x}}:(1+\mathrm{a}) \alpha \beta \mathrm{mF} \mathrm{F}^{\mathrm{x}} \mathrm{S}^{\mathrm{y}}: \mathrm{am}^{2} \beta^{2} \mathrm{~S}^{\mathrm{y}} \mathrm{S}^{\mathrm{y}}
$$

For example, in the endosperm ADH of T. smallii $(2 \mathrm{n}=20), \mathrm{F}, \mathrm{H}$ and $\mathrm{S}$ bands are seen on the zymograms, and their relative staining intensities are given by expanding $\left(3 \mathrm{mF}^{\mathrm{s}}+3 \mathrm{~S}^{\mathrm{s}}\right)^{2}$ as $\mathrm{m}^{2} \mathrm{~F}^{\mathrm{s}} \mathrm{F}^{\mathrm{s}}$ ( $\mathrm{F}$ band) $:(1+\mathrm{a}) \mathrm{mF}^{\mathrm{s}} \mathrm{S}^{\mathrm{s}}$ (H band) :aS $\mathrm{S}^{\mathrm{s}} \mathrm{S}^{\mathrm{s}}$ (S band), where $\mathrm{F}^{\mathrm{s}}$ and $\mathrm{S}^{\mathrm{s}}$ are the $\mathrm{ADH}$ monomers coded by $A d h^{F(S)}$ and $A d h^{\mathrm{s}(\mathrm{S})}$, respectively. Let $a=1$ and $m=1 / 10$, then we have an expected ratio, $0.01: 0.2: 1$ for respective band intensities on the zymograms of T. smallii. In T. kamtschaticum $\times T$. tschonoskii, genomic constitution of the $F_{1}$ endosperm would be $\mathrm{K}_{1} \mathrm{~K}_{1} \mathrm{~K}_{2} \mathrm{~T}$ according to Haga's supposition of genomic differentiation. Let $\mathrm{F}^{*}$, $\mathrm{S}^{\tau}$, and $\mathrm{S}^{\tau^{\prime}}$ be respective $\mathrm{ADH}$ polypeptide subunits specified by $A d h^{F(K)}$, $A d h^{s_{1}(T)}$ and $A d h^{S_{2}^{(T)}}$ : If the ADH locus of $T$. tschonoskii is such a monoallelic constitution as $A d h^{S_{1}(T)} / A d h^{S_{1}(T)} / A d h^{S_{1}(T)} / A d h^{S_{1}(T)}$ or $A d h^{S_{2}(T)} / A d h^{S_{2}(T)} / A d h^{S_{2}(T)} /$ $A d h^{s_{2}(T)}$, respective bandmorphs expected would be given by expanding $\left(2 \mathrm{~F}^{\kappa}+2 \mathrm{~S}^{\tau}\right)^{2}$ or $\left(2 \mathrm{~F}^{\kappa}+2 \mathrm{~S}^{\tau^{\prime}}\right)^{2}$. If the locus is such a diallelic constitution as $A d h^{S_{1}(T)} /$ $A d h^{S_{2}(T)} / A d h^{\mathrm{S}_{2}(T)} / A d h^{\mathrm{S}_{2}(T)}$, the bandmorphs and their activities expected would be as follows: $\left(2 \mathrm{~F}^{\kappa}+\mathrm{S}^{\tau}+\mathrm{mS}^{\tau^{\prime}}\right)^{2} \rightarrow 4 \mathrm{~F}^{\star} \mathrm{F}^{\star}$ (F band) $+4 \mathrm{mF}^{\star} \mathrm{S}^{\tau^{\prime}}$ (a hybrid band) + $4 F^{\wedge} S^{\tau}$ (H band $)+m^{2} S^{\tau^{\prime}} \mathbf{S}^{\tau^{\prime}}\left(S_{8}\right.$ band $)+2 m S^{\tau} S^{\tau^{\prime}}\left(S_{2}\right.$ band $)+S^{t} S^{\tau}\left(S_{1}\right.$ band). We are interested in relative staining intensities of only three main bands on the zymograms for a technical convenience. Thus assuming that $F^{\star} F^{\kappa}$ and $S^{\varepsilon^{\prime}} S^{\tau^{\prime}}$ have the same activity and minor hybrid bands are ignored (or $\mathrm{m} \fallingdotseq 0$ ), respective relative staining intensities in $F, H$ and $S$ bandmorphs are to be $1: 2: 1$ in the first case and 4:4:1 in the second case. Yields of $\mathrm{S}^{\tau^{\prime}} \mathbf{S}^{\tau^{\prime}}$ will be discussed in the forthcoming section.

Likewise, the relative staining intensities expected are given by expanding $\left(2 \mathrm{~F}^{\mathrm{s}}+\mathrm{mF}^{\mathrm{s}}+\mathrm{S}^{s}\right)^{2}$ for the endosperm $\mathrm{ADH}$ of the kamtschaticum $\times$ smallii cross, where $F^{*}, F^{s}$ and $S^{s}$ are polypeptide subunits of each ADH isozyme specified by $A d h^{F(\boldsymbol{K})}, A d h^{F(S)}$ and $A d h^{S(S)}$, respectively; letting respective yields of $\mathrm{F}^{*}, \mathrm{~F}^{\mathrm{s}}$ and $S^{s}$ monomers be $1,1 / 10$ and 1 , the relative staining intensities would be $6.21: 5.10: 1.00$ for $\mathrm{F}, \mathrm{H}$ and $\mathrm{S}$ bands. The same principle may be applicable to the ADH activity of all the remaining hybrids, as summarized in Table 5.

So far as photographs of respective zymograms are concerned (Fig. 2), effect of gene dosage seems to be additive in the $\mathrm{ADH}$ activity. However, more elaborated studies are of necessity for further confirmation, because the limited gene activating factor is known in maize (e.g., Schwartz 1976). In this connection, attention should be paid to the fact that the relative staining intensities were very close to $1: 2: 1$ in the $\mathrm{F}_{1}$ endosperm of the kamtschaticum $\times$ tschonoskii cross and also close to $1: 8: 16$ in its reciprocal cross for $\mathrm{F}, \mathrm{H}$ and $\mathrm{S}$ bands, respectively. 
Table 5. Relative staining intensities of respective bandmorphs expected in the $F_{1}$ progenies of interspecific crosses

\begin{tabular}{|c|c|c|c|c|c|}
\hline \multirow{2}{*}{ Cross types* } & \multirow{2}{*}{$\begin{array}{l}\text { Genomes in } \\
\text { endosperm }\end{array}$} & \multirow{2}{*}{$\begin{array}{l}\text { Alleles in } \\
\text { endosperm** }\end{array}$} & \multicolumn{3}{|c|}{ Relative staining intensities*** } \\
\hline & & & $\mathbf{F}$ & $\mathbf{H}$ & $\mathbf{S}$ \\
\hline kamt $\times t s c h$ & $\mathrm{~K}_{1} \mathrm{~K}_{1} \mathrm{~K}_{2} \mathrm{~T}$ & $F^{x} F^{x} S^{\tau} \mathbf{S}^{\prime}$ & 1.00 & 2.00 & 1.00 \\
\hline$t s c h \times k a m t$ & $\mathrm{~K}_{1} \mathrm{~K}_{2} \mathrm{~K}_{2} \mathrm{TT}$ & $F^{*} S^{\tau} \mathbf{S}^{\tau} \mathbf{S}^{\tau^{\prime}} \mathbf{S}^{\tau^{\prime}}$ & 1.00 & 8.00 & 16.00 \\
\hline kamt $\times s m a l$ & $\mathrm{~K}_{1} \mathrm{~K}_{1} \mathrm{SU}$ & $F^{x} F^{*} F^{s} S^{s}$ & 6.20 & 5.10 & 1.00 \\
\hline smal $\times$ kamt & $\mathrm{K}_{1} \mathrm{SSUU}$ & $F^{*} \mathrm{~F}^{s} \mathrm{~F}^{\mathrm{s}} \mathrm{S}^{\mathrm{s}} \mathrm{S} s$ & 1.00 & 3.33 & 2.77 \\
\hline$t s c h \times s m a l$ & $\mathrm{~K}_{2} \mathrm{~K}_{2} \mathrm{TTSU}$ & $F^{s} S^{s} S^{\tau} S^{\tau} S^{\tau^{\prime}} \mathbf{S}^{\tau^{\prime}}$ & 1.00 & 100.00 & 250.00 \\
\hline $8 m a l \times t s c h$ & $\mathrm{~K}_{2}$ TSSUU & 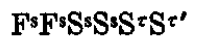 & 1.00 & 20.00 & 400.00 \\
\hline
\end{tabular}

* Abbreviation: T. kamtschaticum (kamt), T. tschonoskii (tsch), T. smallii (smal).

** $A d h^{F(K)}=\mathrm{F}^{*}, A d h^{\mathrm{S}_{1}(T)}=\mathrm{S}^{\tau}, A d h^{\mathrm{S}_{2}(T)}=\mathrm{S}^{\tau^{\prime}}, A d h^{F(S)}=\mathrm{F}^{\mathrm{S}}$ and $A d h^{S(S)}=\mathrm{S}^{\mathrm{S}}$.

*** Figures given are calculated by the assumption of $\mathbf{S}^{\tau}=\mathbf{S}^{\tau^{\prime}}$. For further explanation, see the text.

\section{3) Operation of modifier genes}

In the previous section, we introduced an $m$ factor for a yield ratio of $\mathrm{F}^{\mathrm{x}}$ to $\mathrm{S}^{\mathrm{y}}$ monomer. This means that the $\mathrm{S}^{\mathrm{y}}$ monomer is controlled by a regulating factor for its yield. When we assigned $m=0.1$ for the yield of polypeptide subunits coded by $A d h^{F(s)}$, the staining intensities of respective bandmorphs were well documented for the ADH activity of $T$. smallii as well as of the $F_{1}$ progeny raised by crossing between the species and others. Therefore this regulating factor must be inherited as a Mendelian fashion.

Another example was seen in T. tschonoskii. We obtained the following results: (1) the $\mathrm{ADH}$ electromorphs suggest that the isozymes are specified by two alleles, $A d h^{S_{1}(T)}$ and $A d h^{S_{2}(T)}$; (2) the relative staining intensities for $\mathrm{F}, \mathrm{H}$ and $S$ bands were close to $1: 2: 1$ in the $F_{1}$ endosperm of the kamtschaticum $\times$ tschonoskii cross and 1:8:16 in its reciprocal cross; (3) the $S_{2}$ band which may be a hybrid isozyme specified by $A d h^{S_{1}(T)}$ and $A d h^{S_{2}(T)}$ recovered always in the above hybrids but the $\mathrm{F}^{\star} \mathrm{S}^{\mathrm{r}^{\prime}}$ band which may be a hybrid isozyme specified by $A d h^{F(\mathbb{K})}$ and $A d h^{S_{2}(T)}$ recovered almost, if not perfectly, invisibly; (4) the result of in vitro hybridization test between isozymes of kamtschaticum and tschonoskii excluded the possibility of unsynchronized molecular hybridization in vivo in the ADH subunits. Accordingly, we postulate that a modifier gene operates upon the yield of $\mathbf{S}^{\tau^{\prime}}$ polypeptide subunit and the following explanation is concerned with the $\mathrm{F}^{\wedge} \mathrm{S}^{z^{\prime}}$ heterodimer: Respective molecular conformations in $\mathrm{F}^{\kappa}$, $S^{\tau}$ and $S^{x^{\prime}}$ polypeptide subunits do not inhibit dimerization between themselves, $F^{\kappa}$ and $S^{\tau}$, and $S^{\tau}$ and $S^{\tau^{\prime}}$ but between $F^{\kappa}$ and $S^{\tau^{\prime}}$.

\section{4) Substrate specificity}

Our primary interest in the problem was allocated for its evolutionary 
consequence, because every organism possesses alcohol dehydrogenase activity yet remarkable substrate specificity exists among different sources of the enzyme (cf. Sund and Theorell 1963), even in different sites of subunits of horse liver ADH (Pietruszko 1975).

The present results suggest that the endosperm $\mathrm{ADH}$ of all three species examined has no species specificity as far as staining intensities on the zymograms are compared qualitatively. The endosperm ADH resembles potato ADH rather than that of yeast, Drosophila and mammals as to the following points: (a) methanol is almost as inert as iso-propanol; (b) activity with ethanol is greater than with butanol; (c) cyclohexanol may not be a substrate. This difference may reflect different physiological roles of alcohol dehydrogenase in microorganisms, plants and animals. The plant ADH is generally taken to be the reduction of acetaldehyde formed under anaerobic conditions which occur most frequently during the seed storage under unaired or submerged grounds. On the other hand, current opinion on horse liver $\mathrm{ADH}$ is that its role is to remove ethanol from the blood (Krebs and Perkins 1970), although peroxidases may convert ethanol directly into acetate (cf. Walsh 1973); in Drosophila melanogaster the enzyme seems an absolute necessity for converting ethanol into acetaldehyde (David et al. 1978); isozymes of yeast ADH are specified for functioning in production of ethanol on one side and the other in ethanol utilization. More sophisticated approaches are of necessity for further insight of the problem in relation to the polymorphism of the enzyme.

The authors wish to thank Dr. David L. Mulcahy, University of Massachusetts for his critical reading of the earlier draft of the manuscript. We also want to thank two anonymous reviewers for their perceptive criticisms of the manuscript. One of the authors (MI) was supported partially by a Grant-in-Aid for Scientific Research No. 312107 to Professor Kozo Imahori from the Ministry of Education, Science and Culture, which is grateful.

\section{REFERENCES}

David, J., Bocquet, C., Van Herrewege, J., Fouillet, P. and Arens, M. -F. (1978) Alcohol metabolism in Drosophila melanogaster: uselessness of the most active aldehyde oxidase produced by the Aldox locus. Biochem. Genet. 16, 203-211.

Davies, D. D., Patil, K. D., Ugochukwu, E. N. and Towers, G. H. N. (1973) Aliphatic alcohol dehydrogenase from potato tubers. Phytochemistry 12, 523-530.

FIsCHER, R. A. and SCHWARTZ, D. (1973) Dissociation and recombination of maize alcohol dehydrogenase; allelic differences in requirement for zinc. Molec. gen. Genet. 127, 33-38.

FuxUDA, I. (1967) The formation of subgroups by the development of inbreeding system in a Trillium population. Evolution 21, 141-147.

HAGA, T. (1934) The comparative morphology of the chromosome complement in the tribe Paridae. J. Fac. Sci. Hokkaido Imp. Univ. Ser. V. 3, 10-32.

HAGA, T. (1937) Genome and polyploidy in the genus Trillium. I. Chromosome affinity between the genomes. Jpn. J. Genet. 13, 135-145.

HAGA, T. (1951) Genome and polyploidy in the genus Trillium. III. Origin of the polyploid species. Cytologia (Tokyo) 16, 243-258.

HAGA, T. (1958) Differential reactivity of the chromosomes (in Japanese with English summary. Sym. Cell Chem. 7, 101-111. 
HAGA, T. (1969) Structure and dynamies of natural populations of a diploid Trillium. In Chromosome Today Vol. II (ed. C. D. Darlington), pp. 207-217. Oliver and Boyd, Edinburgh.

Haga, T. and Kurabayashi, M. (1952) Genome and polyploidy in the genus Trillium. IV. Genome analysis by means of differential reaction of chromosome segments to low temperature. Cytologia (Tokyo) 18, 13-28.

HAGA, T., WATANABE, H. and KAYANo, H. (1974) Hybridization in natural populations of Japanese trilliums. Jpn. J. Genet. 49, 399-412.

HART, G. E. (1971) Alcohol dehydrogenase isozymes: Dissociation and recombination of subunits. Molec. gen. Genet. 111, 61-65.

HiralZumi, Y. (1956) Evolution and variation in Trillium I. Random genetic drift in natural populations of Trillium kamtschaticum Pall. Jpn. J. Genet. 31, 23-48.

IHARA, M. and ENDo, T. (1978) Genetic control of alcohol dehydrogenase in the Japanese species of Trillium. Ann. Rep. Nat. Inst. Genet. (Japan) no. 28, 40-41.

Kayano, H. and Watanabe, H. (1970) Panmixis in natural populations of Trillium kamtschaticum. Jpn. J. Genet. 45, 59-69.

Kurabayashi, M. (1952) Differential reactivity of chromosomes in Trillium, Journ. Fac. Sci. Hokkaido Univ. Ser. V. 4, 238-248.

Kurabayashi, M. and Saho, T. (1957) Evolution and variation in Trillium. IX. Chromosome complement in two interspecific hybrids newly found. Cytologia (Tokyo) 22, 263-272.

Krebs, H. A. and Perkins, J. R. (1970) The physiological role of liver alcohol dehydrogenase. Biochem. J. 118, 635-644.

NARISE, T. (1956) Variation and evolution in Trillium. III. The breeding system of Trillium kamtschaticum Pall. in some natural populations. Jpn. J. Genet. 31, 65-74.

Pietruszko, R. (1975) Heterogeneity, polymorphism, and substrate specificity of alcohol dehydrogenase from horse liver. In Isozymes Vol. I (ed. C. L. Markert), pp. 707-724. Acad. Press, New York.

Scandalios, J. G. (1974) Isozymes in development and differentiation. Ann. Rev. Plant Physiol. 25, 225-258.

SchWArtz, D. (1976) Regulation of expression of Adh genes in maize. Proc. Natl. Acad. Sci. USA 73, 582-584.

SCHWARTZ, D. and ENDo, T. (1966) Alcohol dehydrogenase polymorphisms in maize-simple and compound loci. Genetics 53, 709-715.

Sund, H. and Threorell, H. (1963) Alcohol dehydrogenase. In The enzymes vol. 7 (ed. P. D. Boyer, H. Lardy, and K. Myrbacks), pp. 25-83. Acad. Press, New York.

TORRES, A. M. (1976) Dissociation-recombination of intergenic sunflower alcohol dehydrogenase isozymes and relative isozyme activities. Biochem. Genet. 14, 87-98.

WALSH, M. J. (1973) The biochemical aspects of alcoholism. In Alcoholism (ed. P. G. Bourne and R. Fox), pp. 43-61. Acad. Press, New York. 